\title{
PULMONARY VASCULAR CHANGES IN A DOG AFTER AORTO- PULMONARY ANASTOMOSIS FOR FOUR YEARS
}

\author{
BY \\ DONALD HEATH, ${ }^{*}$ DAVID E. DONALD, AND JESSE E. EDWARDS \\ From the Mayo Clinic and Mayo Foundation, Rochester, Minnesota, U.S.A. \\ Received June 20, 1958
}

When dogs are subjected to an anastomosis between a large systemic artery and one of the pulmonary arteries, the subsequent progress of events is related to the diameter of the fistula. If this is large, exceeding about $5 \mathrm{~mm}$., there is usually a rapid onset of fatal cardiac failure, as in the animal described by Ekström et al. (1951-52) and in 16 of the 21 dogs reported on by Muller et al. (1953) who anastomosed the aorta with a pulmonary artery. When the communication is small, usually $3 \mathrm{~mm}$. or less in diameter, as it frequently is when the subclavian artery is employed in the anastomosis, the animals survive with a normal or only slightly raised blood pressure in the pulmonary artery, and vascular changes do not occur in the small pulmonary arteries. In a third group where the diameter of the fistula is intermediate in size, the animals survive with pulmonary hypertension, and vascular changes occur (Muller et al., 1953; Ferguson and Varco, 1955). The structural changes described are usually medial hypertrophy and intimal fibrosis, histological features characteristic of an early grade of hypertensive pulmonary vascular disease in the human lung (grades 1 to 3 on the basis of the criteria of Heath and Edwards, 1958). The severe structural changes characterized by generalized and complex local forms of vascular dilatation, which are pathognomonic of the late stages of hypertensive pulmonary vascular disease associated with congenital cardiac septal defects in man (grades 4 to 6), do not appear to have been reported in dogs with artificial aorto-pulmonary anastomosis and generalized pulmonary hypertension. However, vascular changes comparable to these, confined to the left upper lobe, in dogs subjected to an endto-end anastomosis between the left subclavian artery and the pulmonary artery to this lobe have been reported by Dammann et al. (1957). In these animals there was pulmonary hypertension only in the restricted area of lung served by the anastomosis, while the blood pressure in the main pulmonary artery was normal, so that the hæmodynamic conditions cannot be considered as analogous to those found in human disease. Hence up to the present it has not really been established that the complete progression of structural changes seen in human hypertensive pulmonary vascular disease can be experimentally produced in the dog exposed to comparable physiological conditions. In fact the frequency of the severe lesions in man, in contrast to the rarity of them in dogs, suggests that a factor of time in addition to elevation of blood pressure in the pulmonary artery is necessary for their development.

The purpose of this communication is to demonstrate that higher grades of hypertensive pulmonary vascular disease can occur after the experimental production of an aorto-pulmonary anastomosis and generalized pulmonary hypertension. The presence of severe pulmonary vascular changes in one of three dogs subjected to this procedure is reported. The additional ætiological factor is discussed later. The relation between the histological appearance of the pulmonary arteries of these dogs and that of the pulmonary arteries in man in patent ductus arteriosus is also discussed, bearing in mind that the hæmodynamic abnormalities were acquired in the experimental animals but have been present from birth in human disease.

* Working at the Mayo Foundation, Rochester, Minnesota: this is a part of the Graduate School of the University of Minnesota. 


\section{METHOD AND MATERIAL}

A fistula between the systemic and the pulmonary circulation was produced in each of three dogs. It should be pointed out that the animals described in this report had originally been prepared for other studies and not specifically for the present investigation. It was thus not possible to obtain all of the physiological data that might otherwise have been secured. Data relating to sex, age, and body weight of the dogs and the operative procedure and mode of death in each instance are shown in Table I. Cardiac catheterization was performed in dogs 1 and 2, with the results shown in Table II. In dog 3 a biopsy of the right lung was performed 20 months after operation. The dogs died or were killed after the fistulae had been patent for nearly four years.

TABLE I

Data Relating to Operative Procedures

\begin{tabular}{|c|c|c|c|c|c|c|c|c|}
\hline \multirow{3}{*}{ Dog } & \multirow{3}{*}{$\begin{array}{c}\text { Body } \\
\text { weight,* } \\
\text { kg. }\end{array}$} & \multicolumn{3}{|c|}{ Anastomosis } & \multirow{3}{*}{$\begin{array}{l}\text { Survival, } \\
\text { months }\end{array}$} & \multirow{3}{*}{$\begin{array}{c}\text { Mode } \\
\text { of } \\
\text { death } \dagger\end{array}$} & \multirow{2}{*}{\multicolumn{2}{|c|}{$\begin{array}{l}\text { Months from establishment } \\
\text { of anastomosis to: }\end{array}$}} \\
\hline & & \multirow{2}{*}{ Type } & \multirow{2}{*}{$\begin{array}{l}\text { Pulm. } \\
\text { artery } \\
\text { used }\end{array}$} & \multirow{2}{*}{$\begin{array}{l}\text { Mm. beyond } \\
\text { pul. trunk } \\
\text { bifurc. }\end{array}$} & & & & \\
\hline & & & & & & & $\begin{array}{c}\text { Cardiac } \\
\text { catheterization }\end{array}$ & $\begin{array}{l}\text { Biopsy } \\
\text { of lung }\end{array}$ \\
\hline 1 & $12 \cdot 3$ & $\begin{array}{l}\text { Modified } \\
\text { Blalock } \ddagger\end{array}$ & $\mathbf{R}$ & 20 & 47 & $\mathrm{C}$ & 47 & None \\
\hline 2 & $13 \cdot 6$ & $\begin{array}{l}\text { Modified } \\
\text { Blalock } \ddagger\end{array}$ & L & 11 & 47 & $\mathrm{~K}$ & 47 & None \\
\hline 3 & $17 \cdot 0$ & Potts & $\mathrm{L}$ & - & 46 & $\mathrm{~K}$ & - & 20 \\
\hline
\end{tabular}

* Weight at time of operation. Dogs 1 and 2 were adult and dog 3 was aged 8 months. All were male.

$+\mathbf{C}=$ died after cardiac catheterization; $\mathrm{K}=$ killed.

$\ddagger$ The brachiocephalic trunk was used in the anastomosis.

TABLE II

Data Obtained at Cardiac Catheterization

\begin{tabular}{c|c|c|c|c|c}
\hline \multirow{2}{*}{ Dog } & \multirow{2}{*}{$\begin{array}{c}\text { Months after } \\
\text { anastomosis } \\
\text { established }\end{array}$} & \multicolumn{4}{|c}{ Blood pressure, mm. of Hg } \\
\cline { 3 - 6 } & & $\begin{array}{c}\text { Right } \\
\text { atrium }\end{array}$ & $\begin{array}{c}\text { Right } \\
\text { ventricle }\end{array}$ & $\begin{array}{c}\text { Pulmon. } \\
\text { artery }\end{array}$ & Aorta \\
\hline 1 & 47 & $0 /-3$ & $37 /-3$ & $31 / 17$ & $170 / 125$ \\
\hline 2 & 47 & -5 & $28 /-10$ & $22 / 10$ & $210 / 159$ \\
\hline
\end{tabular}

At necropsy in each case the weight of each ventricle and the total heart weight were measured, together with the thickness of each ventricle. The ratio of the weight of the left ventricle to that of the right was calculated in each instance, together with the ratio of the weight of each ventricle and of the whole heart respectively to the total body weight. The diameter of the fistula was measured. These pathological data are shown in Table III. A portion of lung from each lobe of both lungs was embedded in paraffin. Sections of lung were stained by the Lawson modification of the Weigert-Sheridan method to demonstrate elastic tissue, and counterstained with van Gieson's stain to demonstrate muscle and collagen. Serial sections of the material from the left lower lobe in $\operatorname{dog} 3$ were examined. The grade of hypertensive pulmonary vascular disease according to the criteria of Heath and Edwards (1958) was assessed in each instance. 
TABLE III

Pathological Data in Dogs with Aorto-Pulmonary Anastomoses

\begin{tabular}{|c|c|c|c|c|c|c|c|c|c|c|c|c|c|}
\hline \multirow{3}{*}{ Dog* } & \multirow{3}{*}{$\begin{array}{l}\text { Body } \\
\text { weight, } \\
\text { kg. }\end{array}$} & \multicolumn{8}{|c|}{ Weight and ratio to body weight $\dagger$} & \multirow{2}{*}{\multicolumn{2}{|c|}{$\begin{array}{c}\text { Myocardial } \\
\text { thickness, } \\
\text { mm. }\end{array}$}} & \multirow{3}{*}{$\begin{array}{c}\text { Diameter } \\
\text { of } \\
\text { fistula, } \\
\mathrm{mm} \text {. }\end{array}$} & \multirow{3}{*}{$\begin{array}{c}\text { Grade } \\
\text { of } \\
\text { HPVD }\end{array}$} \\
\hline & & \multicolumn{2}{|c|}{ RV } & \multicolumn{2}{|c|}{ LV } & \multirow{2}{*}{$\underset{\mathrm{g} .}{\mathrm{ROH},}$} & \multirow{2}{*}{$\frac{L V}{R V}$} & \multicolumn{2}{|c|}{ Total } & & & & \\
\hline & & g. & $\mathbf{R} \ddagger$ & g. & $\mathbf{R} \ddagger$ & & & g. & $\mathbf{R} \ddagger$ & RV & LV & & \\
\hline 1 & $12 \cdot 3$ & 22 & $1 \cdot 8$ & 65 & $5 \cdot 3$ & 18 & $3 \cdot 0$ & 105 & $8 \cdot 5$ & 3 & 14 & 1 & 0 \\
\hline 2 & $13 \cdot 6$ & 30 & $2 \cdot 2$ & 108 & $8 \cdot 0$ & 25 & $3 \cdot 6$ & 163 & $12 \cdot 0$ & 4 & 13 & 4 & 0 \\
\hline 3 & $17 \cdot 0$ & 60 & $3 \cdot 5$ & 102 & $6 \cdot 0$ & 40 & $1 \cdot 7$ & 202 & $11 \cdot 9$ & 5 & 13 & 5 & $\begin{array}{l}\mathrm{RL}=1 \\
\mathrm{LL}=6\end{array}$ \\
\hline
\end{tabular}

* Dogs listed in order of increasing absolute weight of right ventricle.

$\dagger$ Key: $R V=$ right ventricle; $R=$ ratio; $L V=$ left ventricle; $R O H=$ rest of heart; HPVD=hypertensive pulmonary vascular disease; $\mathrm{RL}=$ right lung; $\mathrm{LL}=$ left lung; $\mathrm{LV} / \mathrm{RV}=$ ratio of weight of left ventricle to weight of right ventricle.

$\$$ The ratios given in these columns are to be multiplied by $10^{-3}$. Normal ratios are as follows (Herrmann, 1925).

$\mathrm{LV}$ : mean, 3.7 ; range, 2.7 to 4.7 . Total: mean, 8.0 ; range, 6.0 to 10.0 . LV/RV: mean, 1.4 ; range, 1.2 to 1.8 . $\mathrm{RV}$ : mean, $2 \cdot 6$; range, $1 \cdot 8$ to $4 \cdot 0$.

\section{RESULTS}

Ventricular Weights (Table III).- The ratio of the total heart weight to total body weight was in the normal range in dog 1 but was abnormally high in dogs 2 and 3.

In dogs 1 and 2 the ratios of the weight of the left ventricle to that of the right were 3.0 and 3.6 respectively, values exceeding the normal mean of 1.4 (range 1.2 to 1.8 ) (Herrmann, 1925). In $\operatorname{dog} 3$ the corresponding ratio was $1 \cdot 7$, a value within the normal range, because both ventricles had hypertrophied: in this dog the ratio of right ventricular weight to total body weight was $3 \cdot 5,{ }^{*}$ the normal mean value being $2 \cdot 6$.

In summary, dog 1 showed no increase in total heart weight. Dog 2 had cardiac enlargement mainly due to left ventricular hypertrophy. Dog 3 had cardiac enlargement with right and left ventricular hypertrophy.

Histological Observations. Structural changes in the small pulmonary arteries occurred only in $\operatorname{dog} 3$, and for this reason it is considered first.

Dog 3. Biopsy of the right lung revealed that the muscular pulmonary arteries were thick walled. Many small arterioles had thick muscular walls. There was intimal fibrosis of many vessels less than $100 \mu$ in diameter whose walls consisted of a single elastic lamina. It is impossible to say whether these vessels were arterioles or venules.

Necropsy disclosed that the histological appearance of the pulmonary arteries in the right lung was different from that in the left, for while arteries of the right lung showed only medial hypertrophy those of the left showed severe hypertensive changes.

In the left lung many of the muscular arteries were hypertrophied (Fig. 1A) while others were dilated and had a thin media. In the lower lobe the mean medial thickness was equivalent to 15 per cent of the external diameter of the vessel. In the upper lobe the corresponding value was 20 per cent. Practically all the muscular arteries were severely or totally occluded by acellular fibrous tissue that stained bright red with van Gieson's stain (Fig. 1A). The walls of pulmonary arterioles as little as $25 \mu$ in diameter consisted of a thick muscular media with internal and external elastic laminæ: most were completely occluded by acellular fibrous tissue (Fig. 1B).

The branches of many of the muscular pulmonary arteries in the left lung were severely dilated and filled with proliferated endothelium (Fig. 1C). These were very similar in structure to the plexiform type of "dilatation lesion" that characterizes the terminal stage of generalized and localized dilatation of pulmonary arteries and arterioles in hypertensive pulmonary vascular disease in man. In some sections, where the continuity of these micro-aneurysms with the parent muscular

\footnotetext{
* In the ratios of heart weight to body weight the values given herein should be multiplied by the factor $10^{-3}$.
} 


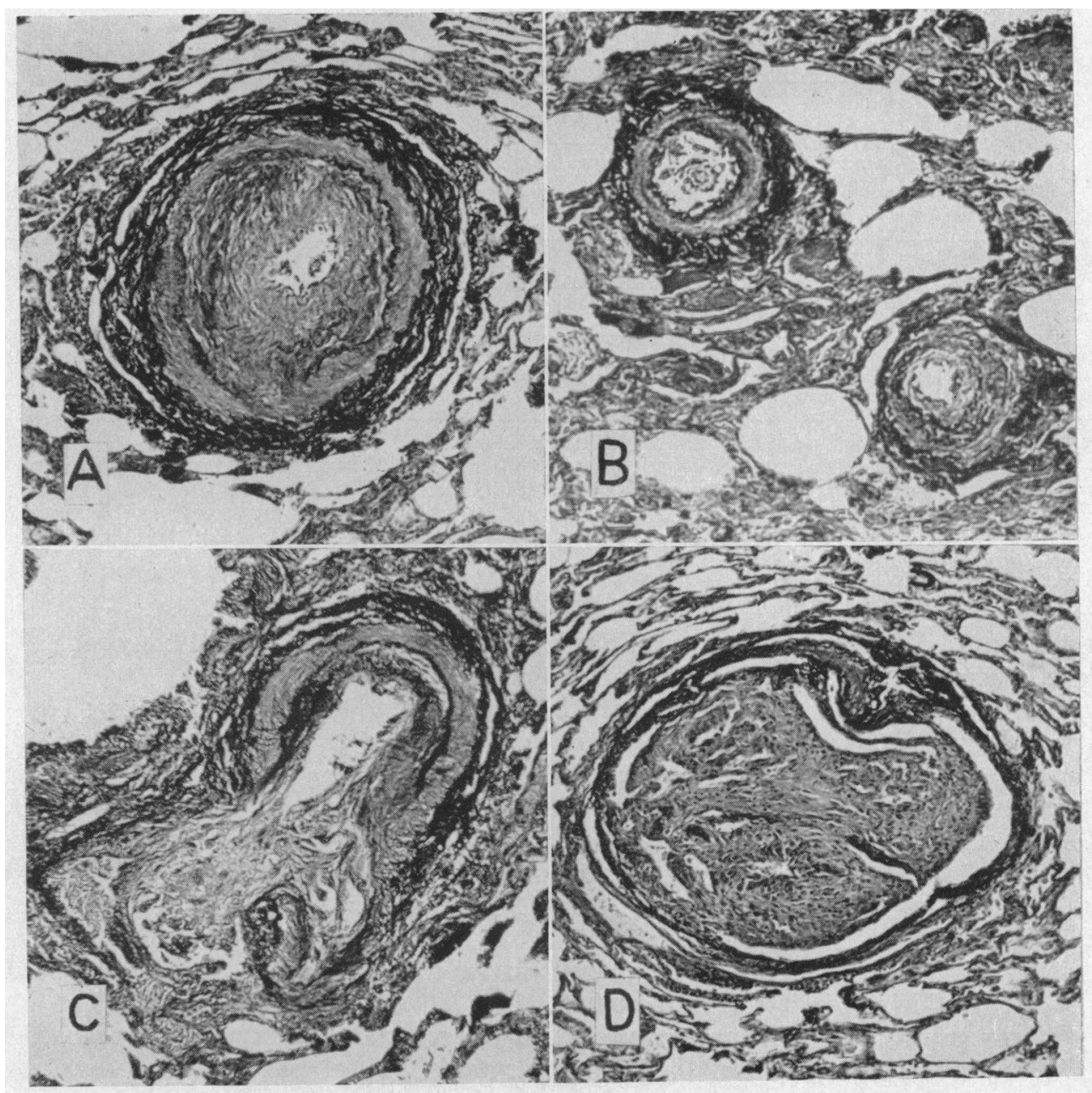

FIG. 1.-Sections are from the left lower lobe of Dog 3. (A) Transverse section of a muscular pulmonary artery. There is medial hypertrophy and the vessel is almost totally occluded by fibrous tissue, most of which is acellular. $\times 100$. (All sections were stained to demonstrate elastic tissue by the Lawson modification of the Weigert-Sheridan method and counterstained with van Gieson's stain to demonstrate muscle and collagen.) (B) Transverse section of two pulmonary arterioles. In both there is a thick muscular media between distinct internal and external elastic laminæ. The arteriole to the right is partially occluded by acellular fibrous tissue, and the underlying muscular media is thinned. There is no intimal fibrosis and no thinning of the media in the arteriole to the left. $\times 200$. (C) Transverse section of a muscular pulmonary artery showing medial hypertrophy, severe acellular intimal fibrosis and a dilated branch which forms a distended sac filled with proliferated cellular endothelium. The appearances are characteristic of those of a "plexiform dilatation" lesion. $\times 150$. (D) Transverse section of a "plexiform dilatation" lesion which forms a distended sac containing proliferated cellular endothelium arranged in parts in a plexiform pattern. An arc of the remaining media of the parent muscular pulmonary artery can be seen at the periphery of the sac $(\times 100)$.

pulmonary artery was not demonstrated, they appeared as dilated sacs filled with proliferated endothelium. In a few instances an arc of the remaining media of the parent muscular pulmonary artery could be seen at the periphery of the distended sac (Fig. 1D).

Some of the occluded muscular arteries in the left lung were the site of necrosis of the media as was exemplified by loss of the characteristic tinctorial properties with the picric acid of van Gieson's stain. In some instances, portions of the media had been lost and replaced by capillary blood 


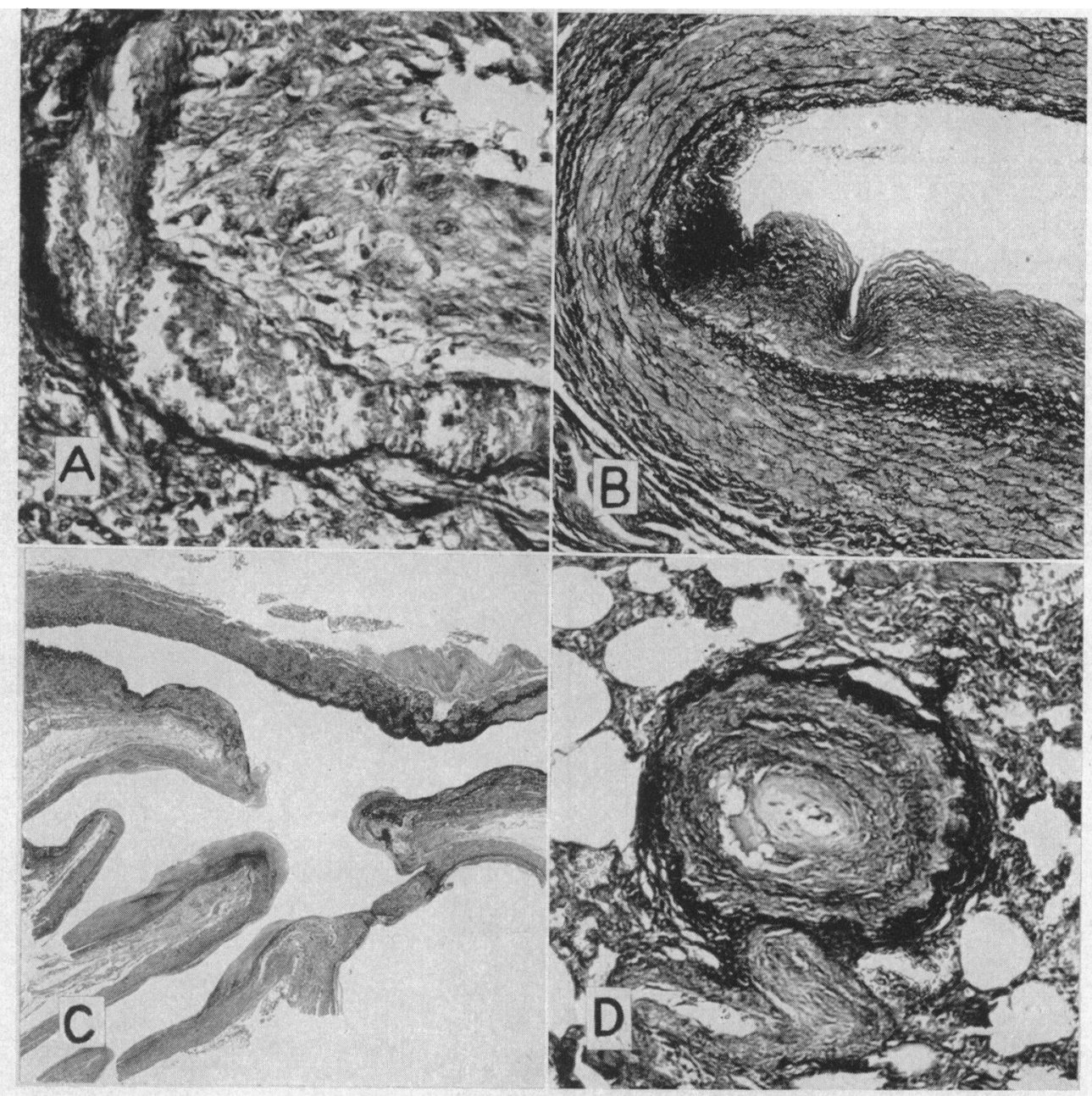

FIG. 2.-Dog 3. (A) Part of a transverse section of a muscular pulmonary artery showing an arc of the necrotic media which has been replaced by a capillary blood vessel. There is reactive cellular intimal fibrosis. $\times 285$. (B) Part of a transverse section of an elastic pulmonary artery showing severe intimal fibro-elastosis. $\times 50$. (C) Longitudinal section through the anastomosis between the aorta, seen running horizontally at the top of the figure, and the left pulmonary artery, seen bent on itself in the lower portion of the figure. The aorta is free of intimal fibrosis except at the immediate junction with the pulmonary vessel. The pulmonary artery is the site of severe intimal fibrosis, the fibrous tissue being acellular and, in many places, hyaline. At many foci the media of the pulmonary trunk is thin. $\times 2$. (D) Transverse section of a dilated arteriole. The wall consists of a thick single elastic lamina. The vessel is almost totally occluded by fibrous tissue which is predominantly acellular. $\times 175$. Figures $2 \mathrm{~A}, 2 \mathrm{~B}$, $2 \mathrm{D}$ and $3 \mathrm{~A}$ are from the left lower lobe.

vessels (Fig. 2A). The necrosis of the media had not initiated an inflammatory cellular response. Other muscular arteries showed an arc in which muscle had been replaced by acellular fibrous tissue, interpreted as healed medial necrosis.

The elastic pulmonary arteries in the substance of the left lung showed intimal fibro-elastosis (Fig. 2B). At the site of anastomosis the media of the pulmonary trunk was thinned and actually lost in some places. There was much acellular intimal fibrosis in this region, and heaped up jet lesions of hyaline collagenous material were present. Fine elastic fibrils, elastic laminæ, and irregularly shaped masses of elastic tissue were found in the intimal fibrous tissue in and around the 
jet lesions (Fig. 2C). Plaques of intimal fibrosis were seen in the aorta. There was no atheroma in the pulmonary arteries.

Many dilated arterioles, the walls of which consisted of only a single elastic lamina, were totally occluded by cellular or acellular fibrous tissue in the left lung (Fig. 2D). The pulmonary veins showed moderate acellular intimal fibrosis but the large pulmonary venous trunks showed little or no intimal reaction. The bronchial arteries, in close apposition to small bronchi, were hypertrophied (Fig. 3A).

The elastic tissue of the pulmonary trunk formed a loosely arranged network of branched, irregularly-shaped fibrils, many of which had clubbed terminal expansions (Fig. 3B). This corresponds to the adult pulmonary configuration that is found in association with acquired pulmonary

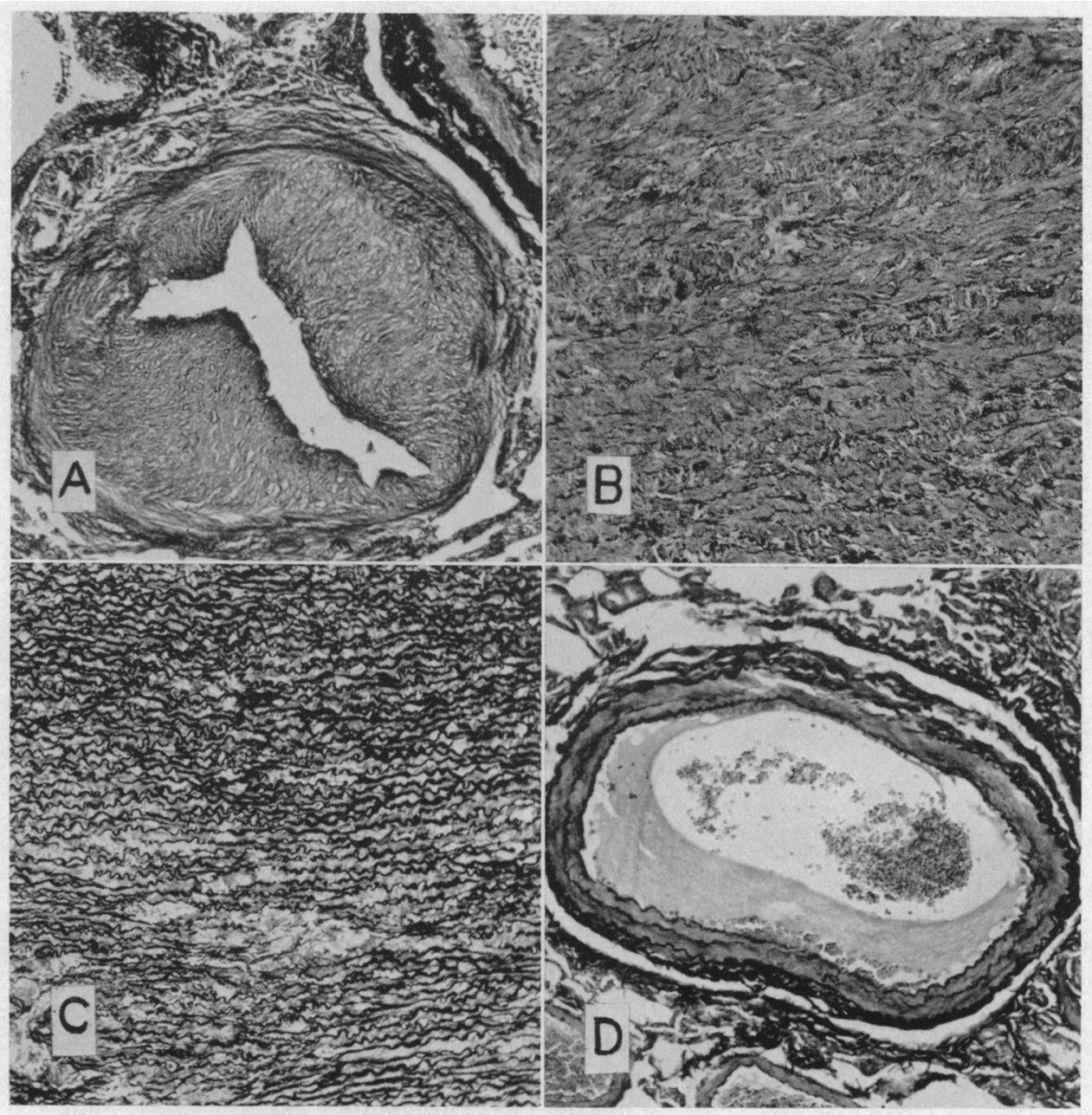

FIG. 3.-Dog 3. (A) Transverse section of a grossly hypertrophied bronchial artery which lies between a bronchus to the left and a muscular pulmonary artery to the right. $\times 175$. (B) Part of a transverse section of the pulmonary trunk. The elastic tissue is of adult pulmonary configuration, consisting of a loosely arranged network of thin, fragmented elastic fibrils. $\times 50$. (C) Part of a transverse section of the aorta. The elastic tissue is of typical aortic pattern, consisting of tightly packed elastic fibrils which are long and uniform and which run parallel with one another. The fibrils are crenated. $\times 50$. (D) Oblique section of a muscular pulmonary artery, from the upper lobe of the right lung. There is hypertrophy of the media but no intimal proliferation. $\times 100$. 
hypertension in hypertensive pulmonary vascular disease in man (Heath et al., 1958a). This appearance contrasted sharply with that of the elastic tissue of the aorta, which took the shape of long, uniform, tightly-packed fibrils running parallel with one another (Fig. 3C).

In the right lung the small muscular pulmonary arteries less than $300 \mu$ in diameter, with very few exceptions, showed only medial hypertrophy with no intimal fibrosis, medial necrosis, or "dilatation" lesions (Fig. 3D). In the lower lobe the thickness of the media reached levels equivalent to 15 per cent of the external diameter of this class of vessel, a value similar to that found in the left lung. In the upper lobe the thickness was less than that found in a corresponding site in the left lung, the greatest thickness found being equivalent to only 10 per cent. A few arteries showed slight acellular intimal fibrosis.

The arterioles with a diameter as little as $35 \mu$ had a thick muscular media with internal and external elastic laminæ, as in the left lung. Some pulmonary arterioles, the walls of which were formed of only a single elastic lamina, were occluded by cellular fibrous tissue. The elastic pulmonary arteries and large muscular pulmonary arteries, exceeding $600 \mu$ in external diameter, showed intimal fibrosis with admixed elastic fibrils.

Spicules of bone were found in the right lower lobe and were not related to the site of biopsy. They were about $900 \mu$ in diameter and occurred either in a subpleural position or next to large muscular arteries (Fig. 4A). There was no hypertrophy of bronchial arteries in the right lung. The pulmonary veins showed acellular intimal fibrosis.

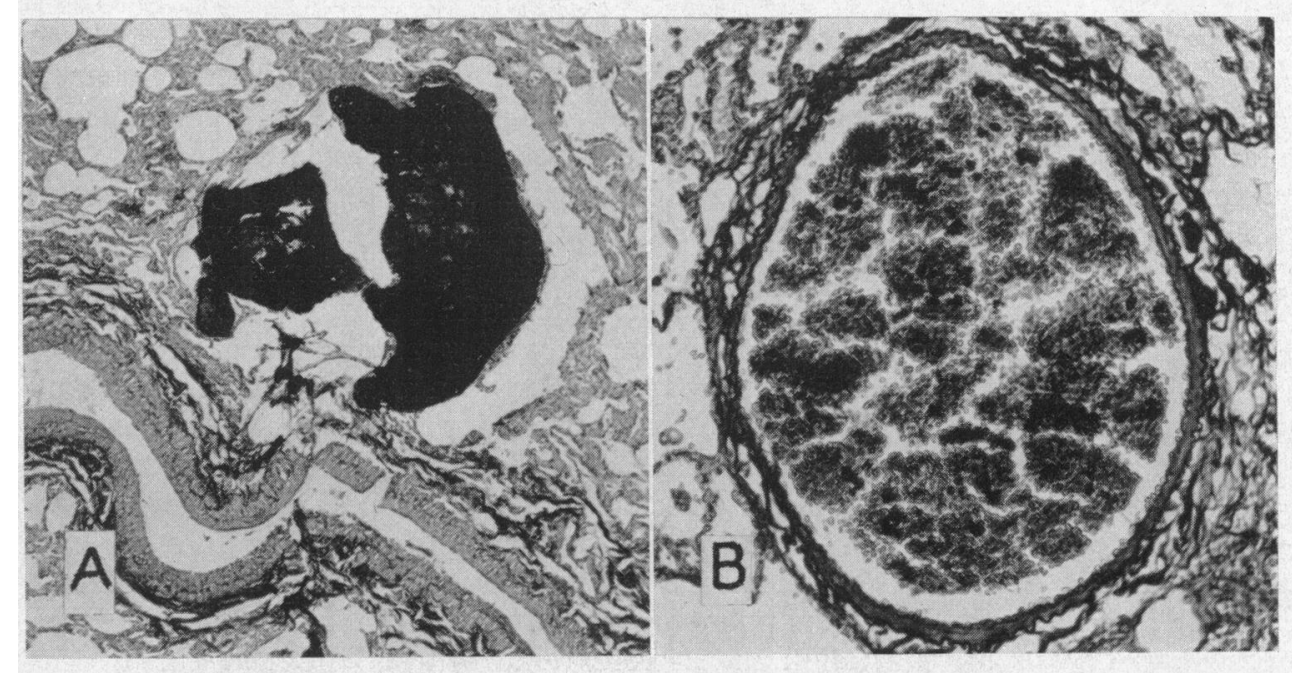

FIg. 4.-(A) Spicule of bone in the parenchyma of the lower lobe of the right lung in dog 3. The spicule is close to a muscular pulmonary artery. $\times 50$. (B) Transverse section of a normal muscular pulmonary artery from the lower lobe of the left lung in a dog not included in the present series. The media is thin and of normal thickness. There is no intimal fibrosis. $\times 175$.

Dogs 1 and 2. The pulmonary arteries were normal in both dogs (Fig. 4B). The thickness of the media in a number of arteries in all lobes was in a range equivalent to 5 to 10 per cent of the external diameter of the vessel; rarely, pulmonary arteries with a medial thickness of up to 13 per cent were seen. In neither of these dogs did numerous pulmonary arterioles have a thick muscular media as in dog 3, although vessels as small as $50 \mu$ in diameter had a distinct, but thin, muscular media with limiting elastic laminæ. There was no intimal fibrosis in pulmonary arteries or arterioles, although all showed acellular intimal fibrosis and thinning of the media at the site of the anastomosis, as described in dog 3. The configuration of elastic tissue in the pulmonary trunk was of the adult pulmonary type as described in dog 3 (Fig. 3B). There was no evidence of bone or of hypertrophy of bronchial arteries. 


\section{COMMENT}

In dogs 1 and 2, in which the diameters of the fistulæ were 1 and $4 \mathrm{~mm}$. respectively, the chronic hæmodynamic conditions produced by the anastomosis were identical with those of a small patent ductus arteriosus in man. In these two dogs, as in man, the small size of the defect was a controlling factor in preventing propagation of the systemic pulse pressure into the pulmonary circulation, so that the mean blood pressure in the pulmonary artery in both dogs was normal (Table II). Under these conditions with normal pulmonary arterial pressures the arteries remained normal in structure, an observation that has also been made in the human lung in patients with a small patent ductus and the classic clinical picture of left ventricular hypertrophy, a high systemic pulse pressure, and the continuous Gibson murmur (Heath and Whitaker, 1955).

In $\operatorname{dog} 3$, in which the diameter of the fistula was $5 \mathrm{~mm}$., the hæmodynamic conditions produced by the defect were probably very similar to those of a large patent ductus in man. The wide communication allowed direct propagation of the systemic pulse pressure to the pulmonary circulation. In this dog the pulmonary arteries underwent the progressive structural changes of hypertensive pulmonary vascular disease as has been noted previously in the human lung in patients with a widely patent ductus (Whitaker et al., 1955). Although detailed clinical studies were not made, the presence of right ventricular hypertrophy and congestive cardiac failure in this dog suggests that there was a state analogous to the peculiarly characteristic clinical syndrome associated with severe pulmonary hypertension (Heath and Whitaker, 1956).

The histological lesions in the left lung were those corresponding to grade 6 hypertensive pulmonary vascular disease according to the criteria of Heath and Edwards (1958). This grade of structural change has been found to be associated in man with a very high pulmonary vascular resistance, an abnormally low pulmonary blood flow, and substantial right-to-left shunts through congenital cardiac defects (Heath et al., 1958b). Grade 6 lesions are associated with pulmonary hypertension that is irreversible after correction of the septal defect, even though this was primarily responsible for the raised pulmonary blood pressure (Heath et al., 1958c). The exceptional occurrence of generalized vascular dilatation and complex localized "dilatation" lesions in dog 3 is considered to be related to the long duration of the patency of the wide artificial aorto-pulmonary anastomosis (4 years). In the more usual type of report dealing with pulmonary vascular change in dogs subjected to anastomotic operations, as exemplified by the paper of Ferguson et al. (1953) in which only medial hypertrophy and intimal fibrosis are described and illustrated, the dogs were killed less than a year after establishment of the anastomosis. Hence the opinion they expressed that "increased pulmonary artery pressure is a principal factor associated with vascular change in the lungs" needs to be elaborated to include the factor of time. Pulmonary hypertension of short duration in man or in experimental animals is associated with medial hypertrophy and probably, in addition, intimal fibrosis (grade 1 to 3 lesions), but severe pulmonary hypertension of long duration in either species produces widespread vascular dilatation and necrosis (grade 4 to 6 lesions). The experiments of Dammann et al. (1957), previously referred to, demonstrate that, if a part of the lung only is suddenly subjected to severe hypertension, the time required for the development of severe structural changes in the pulmonary arteries of that part is much shorter. The pulmonary arteries in a lobe suddenly exposed to a blood pressure of systemic magnitude pass through a series of traumatic changes and eventually show the same structural changes as those described in the present report within as short a period as eleven weeks. Hence, recapitulating to this point, we see that the experimental anastomosis described here reproduced the hæmodynamic and pathological features of the two main clinico-pathological syndromes associated with a patent ductus arteriosus in man. Important differences, however, were observed in the histological appearance and these will now be considered.

In diseases associated with pulmonary hypertension the configuration of the elastic tissue in the pulmonary trunk depends on the time of onset of the increased blood pressure in the pulmonary artery (Heath et al., 1958a). In the normal fœtus the configuration of the elastic fibrils of the pulmonary trunk is similar to that of the aorta, although there are minor differences. In both there 
are many elastic fibrils in the muscle and collagen. These fibrils are long, uniform, crenated, and tightly packed, and are parallel with one another. Although this configuration of elastic tissue remains in the adult aorta, changes normally occur in the pulmonary artery so that the adult appearance is that of a loosely arranged network of branching, irregularly-shaped, fragmented elastic fibrils. A transitional pattern is found in infancy. If pulmonary hypertension is present from birth, as in the presence of a large ventricular septal defect, the media of the pulmonary artery retains the fotal relationship to the aorta and has a similar elastic configuration to that of the aorta (Fig. 3C). If the pulmonary hypertension develops in later life, as in atrial septal defect or mitral stenosis, the configuration of the elastic tissue in the media of the pulmonary artery has undergone the transition into its adult pulmonary form. Applying this to the results of the present investigation, we see that the configuration of elastic tissue in the pulmonary trunk of the dogs with small fistulæ and normal pulmonary pressures was of the adult pulmonary type, as occurs in the human lung in association with a small patent ductus arteriosus. This would be expected since there is no pulmonary hypertension present. The configuration of elastic tissue in the pulmonary trunk in dog 3 was also of the adult pulmonary type, again as would be expected since the pulmonary hypertension in this animal was acquired, as in atrial septal defect or in mitral stenosis in man. Here the analogy to patent ductus arteriosus in man breaks down, for in man the widely patent ductus is congenital and associated from birth with pulmonary hypertension and, as a consequence of this, the elastic tissue of the pulmonary trunk is of fœtal aortic type.

The structural effects associated with pulmonary hypertension on the elastic arteries of dog 3 differed from those seen in comparable vessels in human disease, not only in the media but also in the intima. As already noted, the large muscular pulmonary arteries exceeding about $600 \mu$ in diameter and the elastic pulmonary arteries were the site of severe disseminated acellular intimal fibrosis. Atheroma was not found. In contrast to this, in human disease the large pulmonary arteries become severely atheromatous in patent ductus with severe pulmonary hypertension (Johnson et al., 1950), but non-specific intimal fibrosis in such large vessels is usually conspicuously absent in any form of hypertensive pulmonary vascular disease (Heath and Edwards, 1958).

Another striking feature of the pulmonary vascular pathology in $\operatorname{dog} 3$, not found in the human lung in patent ductus, was the great difference in severity of structural changes in the two lungs, the lesions in the left lung being of grade 6 severity and those in the right being of grade 1 . Since the anastomosis in this dog united the aorta directly with the left pulmonary artery, we consider that the severer lesions in the left lung are caused by the kinetic energy of the stream of systemic blood at high pressure directly impinging on the pulmonary vasculature. The changes in the right lung appear to be associated with the transmitted raised blood pressure in the pulmonary artery without the superadded kinetic effects of the blood stream entering the left pulmonary artery at high velocity.

\section{SUMMARY}

A histological examination was made of the lungs of three dogs subjected to either a modified Blalock or a Potts' procedure four years previously. Severe pulmonary vascular changes, rarely found in dogs, analogous to the severer grades of human hypertensive pulmonary vascular disease, occurred in the animal with the wide aorto-pulmonary anastomosis. These changes are described in detail. The appearance of the elastic tissue of the pulmonary trunk is described and its significance discussed.

Dr. Heath was in receipt of a Rockefeller Travelling Fellowship in Medicine while participating in this investigation which was supported in part by a research grant, No. H3531, from the National Heart Institute, National Institutes of Health, United States Public Health Service.

\section{REFERENCES}

Dammann, J. F., Jr., Baker, J. P., and Muller, W. H., Jr. (1957). Surg. Gynec. Obst., $105,16$.

Ekström, G., Ekman, C.-A., and Möller, T. (1951-52). Acta chir. scand., 102, 296.

Ferguson, D. J., Berkas, E. M., and Varco, R. L. (1953). Surg. Forum., 4, 267.

, and Varco, R. L. (1955). Circulation Res., 3, 1952. 
Heath, D., and Whitaker, W. (1955). J. Path. Bact., 70, 285.

- - , and Edwards, J. E. (1958). Circulation, 8, 533.

Wood, E. H., DuShane, J. W., and Edwards, J. E. (1958a). J. Path. Bact. (in press).

Helmholz, H. F., Jr., Burchell, H. B., DuShane, J. W., and Edwards, J. E. (1958b). Circulation, $18,1155$.

$-,-\ldots,-\longrightarrow,-$ Kirklin, J. W., and Edwards, J. E. (1958c). Circulation, 18, 1167.

Herrmann, G. R. (1925). Amer. Heart J., 1, 213.

Johnson, R. E., Wermer, P., Kuschner, M., and Cournand, A. (1950). Circulation, 1, 1293.

Muller, W. H., Jr., Dammann, J. F., Jr., and Head, W. H., Jr. (1953). Surgery, 34, 363.

Whitaker, W., Heath, D., and Brown, J. W. (1955). Brit. Heart J., 17, 121. 